Article

\title{
tert-Butyl Hydroperoxide (tBHP)-Induced Lipid Peroxidation and Embryonic Defects Resemble Glucose-6-Phosphate Dehydrogenase (G6PD) Deficiency in C. elegans
}

\author{
Hung-Chi Yang ${ }^{1, *,+}$, Hsiang Yu ${ }^{2,+}$, Tian-Hsiang Ma ${ }^{3}{ }^{-}$, Wen-Ye Tjong ${ }^{3}{ }^{\oplus}$, Arnold Stern ${ }^{4}$ \\ and Daniel Tsun-Yee Chiu ${ }^{5,6, *}$ \\ 1 Department of Medical Laboratory Science and Biotechnology, Yuanpei University of Medical Technology, \\ Hsinchu 300102, Taiwan \\ 2 Department of Medical Biotechnology and Laboratory Sciences, College of Medicine, \\ Chang Gung University, Taoyuan 333323, Taiwan; cohsiang@hotmail.com \\ 3 Graduate Institute of Health Industry Technology, College of Human Ecology, Chang Gung University of \\ Science and Technology, Taoyuan 333324, Taiwan; aeroufo@gmail.com (T.-H.M.); \\ claratania_louisregina@yahoo.com (W.-Y.T.) \\ 4 Grossman School of Medicine, New York University, New York, NY 10016, USA; \\ Arnold.Stern@nyulangone.org \\ 5 Research Center for Chinese Herbal Medicine, Graduate Institute of Health Industry Technology, \\ College of Human Ecology, Chang Gung University of Science and Technology, Taoyuan 333324, Taiwan \\ 6 Department of Pediatric Hematology/Oncology, Linkou Chang Gung Memorial Hospital, \\ Taoyuan 333423, Taiwan \\ * Correspondence: hcyang@mail.ypu.edu.tw (H.-C.Y.); tychiu@mail.cgust.edu.tw (D.T.-Y.C.); \\ Tel.: +886-3-6108175 (H.-C.Y.); +886-3-2118999 (ext. 5100) (D.T.-Y.C.); \\ Fax: +886-3-6102327 (H.-C.Y.); +886-3-211-8866 (D.T.-Y.C.) \\ + These authors contributed equally to this work.
}

Received: 30 October 2020; Accepted: 16 November 2020; Published: 18 November 2020

\begin{abstract}
G6PD is required for embryonic development in animals, as severe G6PD deficiency is lethal to mice, zebrafish and nematode. Lipid peroxidation is linked to membrane-associated embryonic defects in Caenorhabditis elegans (C. elegans). However, the direct link between lipid peroxidation and embryonic lethality has not been established. The aim of this study was to delineate the role of lipid peroxidation in $g s p d-1-k n o c k d o w n$ (ortholog of $g 6 p d$ ) C. elegans during reproduction. tert-butyl hydroperoxide (tBHP) was used as an exogenous inducer. Short-term tBHP administration reduced brood size and enhanced germ cell death in C. elegans. The altered phenotypes caused by tBHP resembled GSPD-1 deficiency in C. elegans. Mechanistically, tBHP-induced malondialdehyde (MDA) production and stimulated calcium-independent phospholipase $\mathrm{A}_{2}$ (iPLA) activity, leading to disturbed oogenesis and embryogenesis. The current study provides strong evidence to support the notion that enhanced lipid peroxidation in G6PD deficiency promotes death of germ cells and impairs embryogenesis in C. elegans.
\end{abstract}

Keywords: GSPD-1; tBHP; lipid peroxidation; iPLA; germ cell apoptosis; embryogenesis; C. elegans

\section{Introduction}

Biochemically, the production of nicotinamide adenine dinucleotide phosphate (NADPH) by glucose-6-phosphate dehydrogenase (G6PD) is crucial for cellular reductive biosynthesis and redox homeostasis [1]. NADPH also plays a cytoregulatory role in free radical production through NADPH 
oxidase and nitric oxide synthase [2]. Clinically, G6PD deficiency in humans is an X-linked disorder affecting 400 million people globally and is highly prevalent across malarial endemic regions [3]. Reduced G6PD activity due to a mutation predisposes G6PD-deficient individuals to red cell disorders, including favism, neonatal jaundice and drug- or infection-induced hemolysis. Besides hemolytic anemia related clinical manifestations, other clinical presentations due to G6PD deficiency have not been thoroughly investigated.

Recently, a preponderance of evidence indicates that G6PD is required for embryonic development in animals, as severe G6PD deficiency is lethal to mice [4]. Similar to the G6PD-deficient murine models, the gspd-1-knockdown (ortholog of g6pd) nematode Caenorhabditis elegans (C. elegans) exhibits a severe hatching defect [5]. It also displays multiple embryonic impairments, including abnormal eggshell structure, enhanced permeability, defective polarity and cytokinesis [6]. These membrane-associated defects have been linked to disturbed membrane lipid composition caused by the activation of calcium-independent phospholipase $\mathrm{A}_{2}$ (iPLA) due to elevated lipid peroxidation [6].

Lipid peroxidation plays a role in altered lipid metabolism, membrane structural integrity, redox imbalance and survival in C. elegans [7-9]. The aim of this study was to delineate the role of lipid peroxidation in gspd-1-knockdown C. elegans during reproduction. To induce lipid peroxidation in C. elegans, tert-butyl hydroperoxide (tBHP) was used as an exogenous inducer. $\mathrm{tBHP}$, a short-chain organic hydroperoxide, has been commonly used as a lipid hydroperoxide analog to evaluate the mechanism of biological alterations resulting from oxidative damage $[10,11]$.

The current study revealed for the first time that a short-term tBHP administration can reduce brood size similar to that observed with GSPD-1 deficiency in C. elegans [5]. Such administration also phenocopies elevated germ cell apoptosis induced by GSPD-1 deficiency. Both malondialdehyde (MDA) and iPLA activity were shown to be increased by tBHP administration, which resembles GSPD-1 deficiency in C. elegans [6]. These findings clearly demonstrate that tBHP-mediated lipid peroxidation can render reproductive activities of GSPD- 1 deficient $C$. elegans abnormal due to the activation of iPLA by MDA leading to eventual germ cell death and embryonic lethality.

\section{Results}

\subsection{Temporal Expression of gspd-1 in C. elegans}

To ensure the quantitative expression of housekeeping gene $g s p d-1$, mRNA level of $g s p d-1$ was measured by qPCR in different stages of $C$. elegans (embryo, L3, one-day-old and five-day-old adults). One-day-old adults contained a mature reproductive system and displayed a high level of oogenesis, while five-day-old adults were relatively old so that egg production was almost ceased and displayed a low level of oogenesis. The temporal expression patterns of $g s p d-1$ were as follows: $g s p d-1$ was highly expressed in the one-day-old adult stage (represented as 1.0), followed by moderate expression at the embryonic stage (0.56). Both the L3 stage (0.24) and the five-day-old adult stage (0.37) showed basal levels of $g s p d-1$ expression (Figure 1). These results suggest that $g s p d-1$ is ubiquitously expressed in C. elegans. The elevated levels of $g s p d-1$ in the embryonic and young adult stages are consistent with the notion that the function of GSPD-1 is required for embryogenesis and oogenesis. 


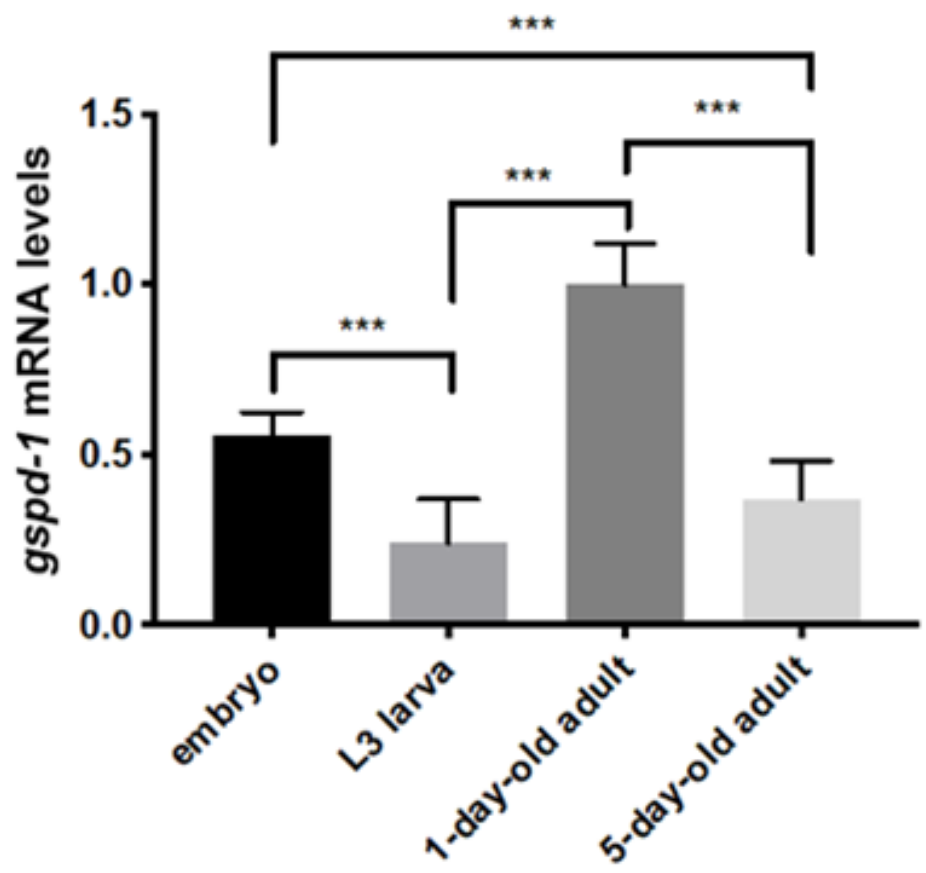

Figure 1. Gene expression pattern of $g s p d-1$ during development by qPCR. The mRNA expression level of $g s p d-1$ in the four C. elegans stages was analyzed by quantitative PCR. The results are presented as the relative expression level and normalized by act-1. Fold change data from three independent experiments are shown as the mean $\pm \operatorname{SD}\left(n=3,{ }^{* * *} p<0.001\right)$.

\section{2. tBHP Reduced Brood Size in C. elegans}

To study whether lipid peroxidation affected embryonic survival, C. elegans were administered with $\operatorname{tBHP}(0.5,1$ and $5 \mathrm{mM})$ followed by determination of brood size. The concentration range of tBHP was based on previous reports $[5,10,12]$. Compared to an un-administered control, 0.5 and $1 \mathrm{mM}$ tBHP did not affect brood size in mock $C$. elegans, while $5 \mathrm{mM}$ tBHP reduced brood size that was similar to gspd-1-knockdown C. elegans (Figure 2). This indicated that short-term administration of $5 \mathrm{mM}$ tBHP is detrimental to embryos. Consistent with a previous result [5], gspd-1-knockdown C. elegans with elevated MDA exhibited a brood size reduction (Figure 2). These results suggest that lipid peroxidation can directly contribute to embryonic lethality.

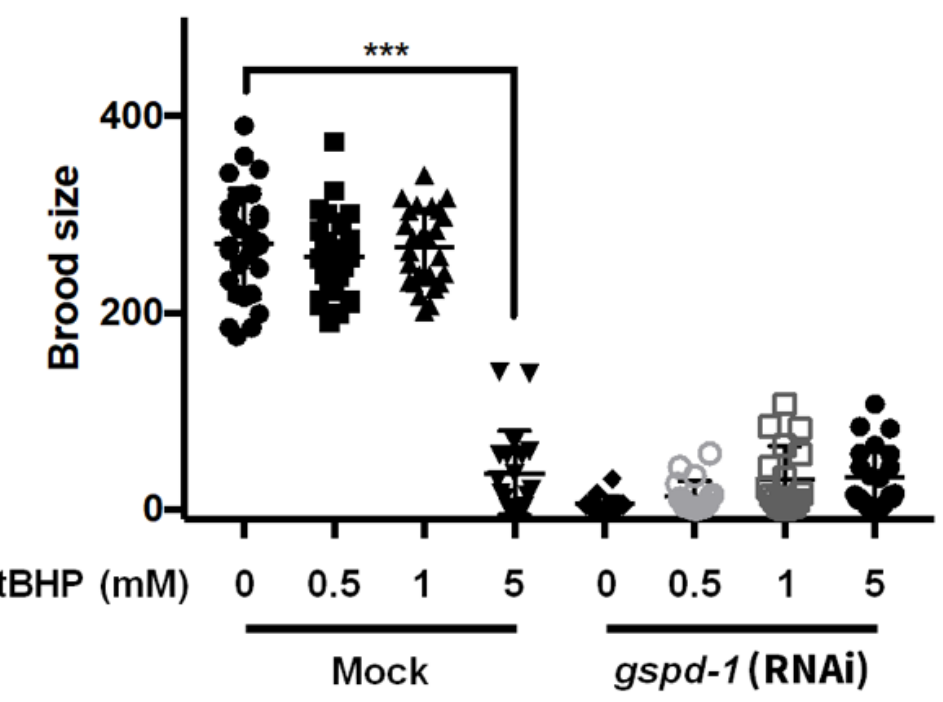

Figure 2. Effect of short-term tBHP administration on brood size. Brood size of mock and gspd-1-knockdown C. elegans with or without tBHP administration $(0.5,1$ and $5 \mathrm{mM})\left({ }^{* * *} p<0.001\right)$. 


\section{3. tBHP Stimulated Germ Cell Apoptosis in C. elegans}

To understand the tBHP effect in the germ cell, the GFP reporter strain bcls39 was used to determine germ cell apoptosis by labeling the somatic sheath cell surrounding the apoptotic germ cells [13]. As shown in Figure 3a,b, mock C. elegans displayed a basal level of germ cell death (4.0 \pm 1.1 apoptotic cells per gonad), whereas germ cell death of gspd-1-knockdown C. elegans was increased $(6.7 \pm 1.2$ apoptotic cells per gonad). The lipid peroxidation induction using $5 \mathrm{mM}$ tBHP enhanced germ cell death in mock $C$. elegans ( $7.7 \pm 1.3$ apoptotic cells per gonad). Moreover, $5 \mathrm{mM}$ tBHP administration toward gspd-1-knockdown C. elegans promoted more apoptotic germ cells than without $5 \mathrm{mM}$ tBHP administration (7.9 \pm 0.9 apoptotic cells per gonad) (Figure $3 b)$. These findings show that tBHP administration toward C. elegans stimulates germ cell apoptosis.

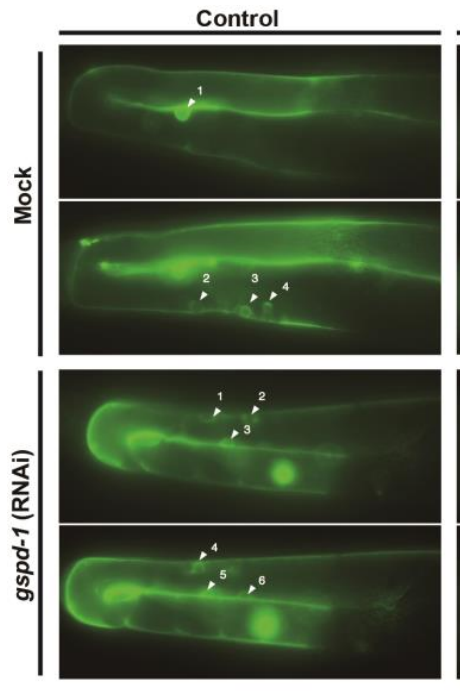

(a)
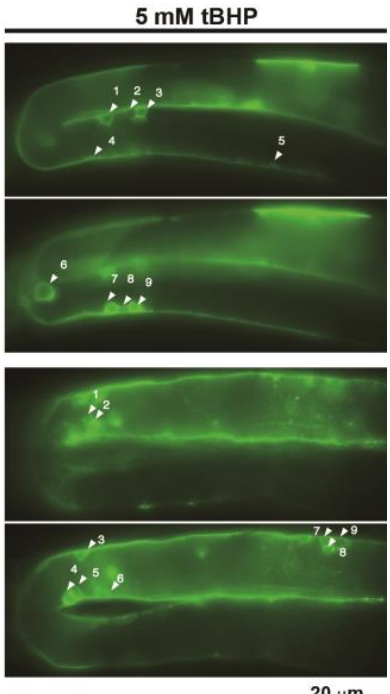

$\underline{20 \mu m}$

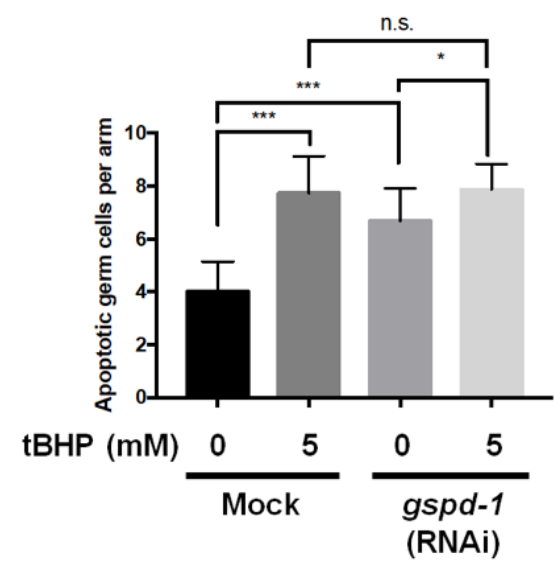

(b)

Figure 3. Short-term of tBHP administration on young adults of mock and gspd-1-knockdown C. elegans promoted germ cell apoptosis. (a) Fluorescent micrographs of apoptotic germ cells (white arrowheads) in the gonad of mock and gspd-1-knockdown C. elegans with or without $5 \mathrm{mM} \mathrm{tBHP}$ (scale bar $20 \mu \mathrm{m}$ ). (b) Mean apoptotic germ cells. Data from three independent experiments are shown as the mean \pm SD ( $n=3$, n.s., not significant; $\left.{ }^{*} p<0.05 ;{ }^{* * *} p<0.001\right)$.

\section{4. tBHP Increased Lipid Peroxidation in C. elegans}

Lipid peroxidation derived from GSPD-1 deficiency has been associated with impaired embryogenesis [6]. Under the basal condition, the MDA level, a frequently measured biomarker of lipid peroxidation, was increased by $27 \%(p<0.05)$ in gspd-1-knockdown C. elegans compared to mock C. elegans (Figure 4 ), while $5 \mathrm{mM}$ tBHP increased the MDA level by $54 \%(p<0.001)$ in administered C. elegans compared to the un-administered mock control. tBHP only increased the MDA level by $26 \%(p<0.05)$ in $g s p d-1$-knockdown C. elegans compared to the un-administered gspd-1-knockdown control (Figure 4). No significant difference in the MDA level after $5 \mathrm{mM}$ tBHP administration was found between gspd-1-knockdown and mock C. elegans. These results indicate that tBHP induces lipid peroxidation in both mock and gspd-1-knockdown C. elegans. 


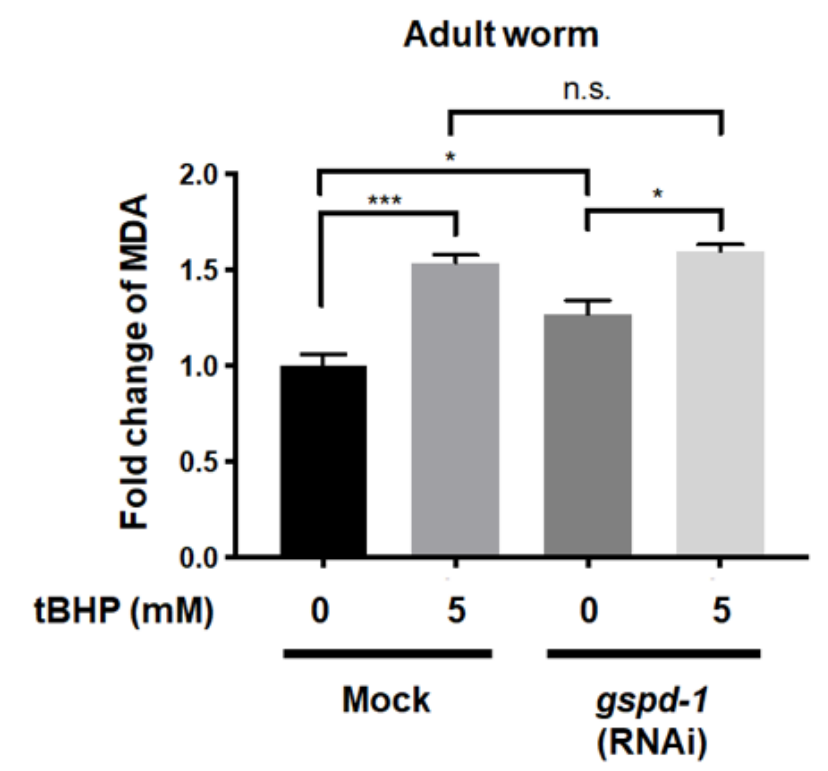

Figure 4. tBHP administration enhanced MDA levels in young adults of mock and gspd-1-knockdown C. elegans. The lipid peroxidation level of mock and gspd-1-knockdown C. elegans with or without $5 \mathrm{mM}$ tBHP was determined. Data from three independent experiments are shown as the mean $\pm \mathrm{SD}(n=3$, n.s., not significant; $\left.{ }^{*} p<0.05 ;{ }^{* *} p<0.001\right)$.

\section{5. tBHP Enhanced iPLA Activity in C. elegans}

To further document that elevated lipid peroxidation could stimulate cytosolic calcium-independent phospholipase $\mathrm{A}_{2}$ (iPLA) [6], the iPLA activity was measured. Consistent with lipid peroxidation results, as shown in Figure 4, tBHP increased iPLA activity in mock C. elegans by $52 \%(p<0.05)$ compared to the un-administered mock control, whereas tBHP promoted iPLA activity by $24 \%(p<0.05)$ in gspd-1-knockdown C. elegans compared to the un-administered gspd-1-knockdown control (Figure 5). This figure also shows that gspd-1-knockdown C. elegans had enhanced iPLA activity by $40 \%(p<0.05)$ compared to mock $C$. elegans and that no significant difference was observed in iPLA activity between gspd-1-knockdown and mock $C$. elegans, both of which were administered with $5 \mathrm{mM} \mathrm{tBHP.}$

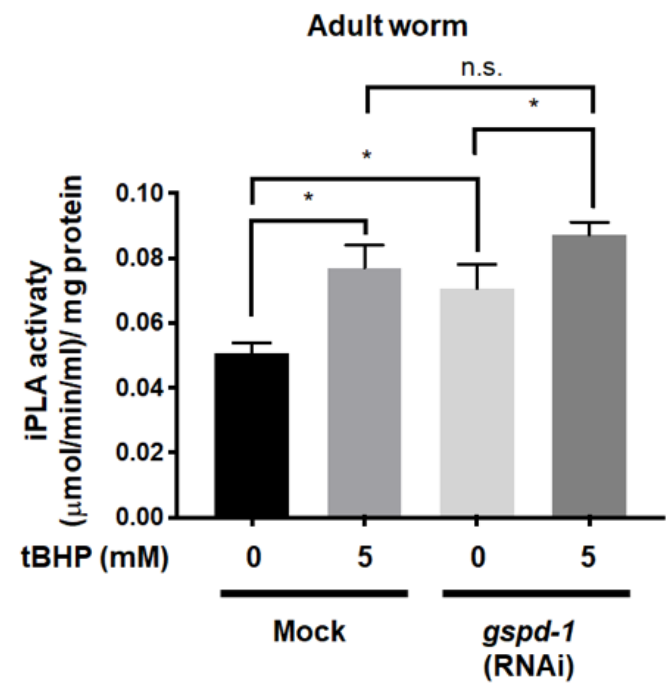

Figure 5. Increased iPLA activity in mock and gspd-1-knockdown C. elegans after short-term tBHP administration. The iPLA activity of mock and gspd-1-knockdown C. elegans with or without $5 \mathrm{mM}$ tBHP was measured. Data from three independent experiments are shown as the mean $\pm \mathrm{SD}(n=3$, n.s., not significant; $\left.{ }^{*} p<0.05\right)$. 


\section{Discussion}

The current study provides direct evidence to support the notion that lipid peroxidation promotes death of germ cells and impairs embryogenesis. All these abnormalities without exogenously added oxidant have been reported in GSPD-1 deficient C. elegans [5,6]. The altered phenotypes caused by short-term tBHP administration resemble GSPD-1 deficiency in C. elegans without the addition of exogenous peroxide [5]. Mechanistic studies indicate that disturbed oogenesis and embryogenesis in C. elegans could be attributed partly to tBHP induced lipid peroxidation as measured by MDA formation leading to stimulated iPLA activity and subsequent defective embryogenesis as proposed in Figure 6.

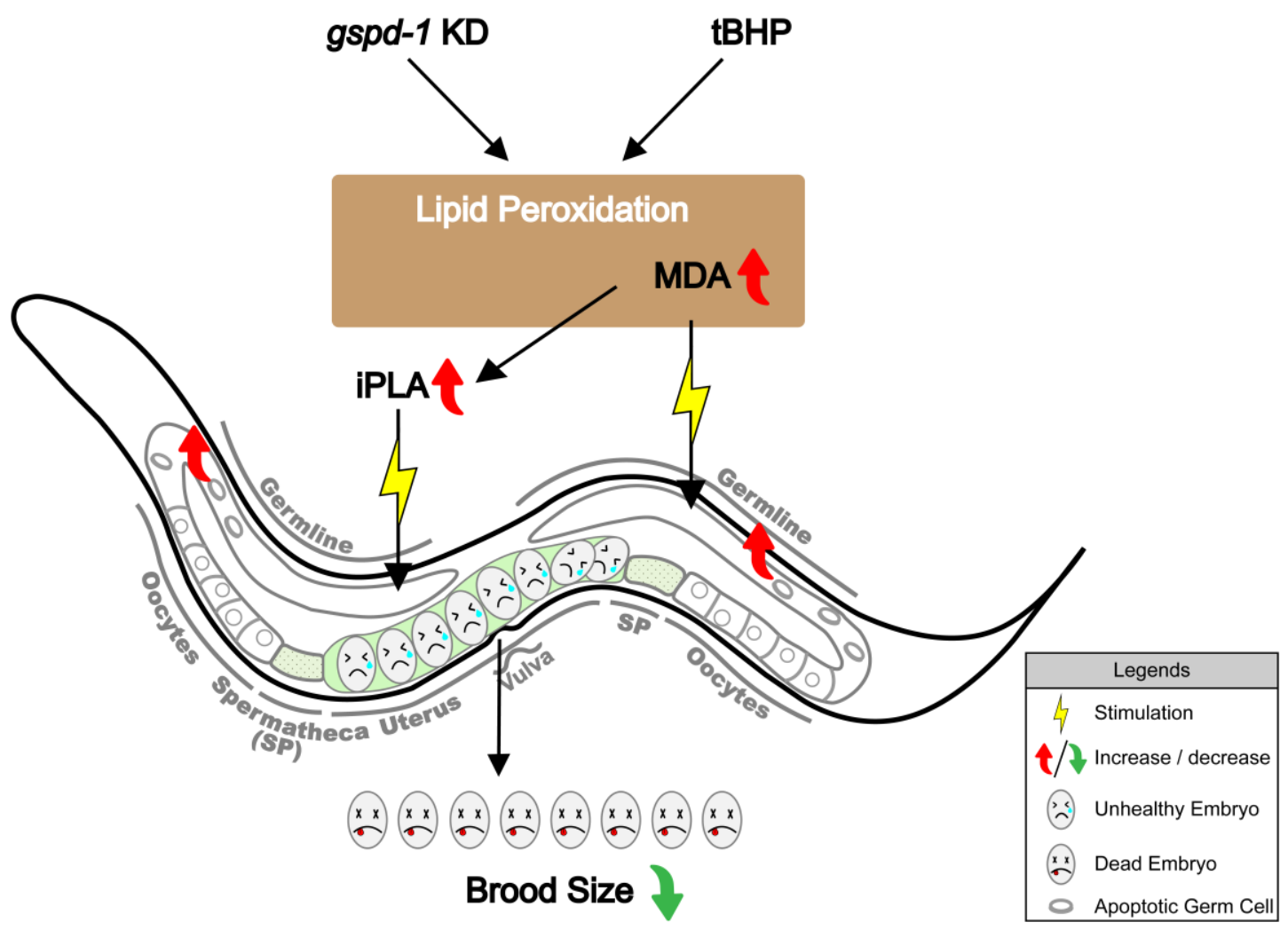

Figure 6. Proposed scheme of tBHP administration resembles GSPD-1 deficiency with increasing lipid peroxidation which can cause directly oxidative damage and enhances iPLA activity leading to increased germ cell death and eventual embryonic lethality.

Elevated oxidative stress and oxidative damage have been considered as a main culprit for promoting death of germ cells and impaired embryogenesis in G6PD-deficient C. elegans [5,6]. An important function of G6PD lies in the regeneration of GSH by providing the reducing equivalent NADPH $[14,15]$. tBHP has been commonly used as a lipid hydroperoxide analog to evaluate the mechanism of biological alterations resulting from oxidative damage $[10,11]$. tBHP produces a peroxyl radical adduct in the absence of NADPH in rat liver microsomal fractions [16]. tBHP is metabolized to tert-butanol at the expense of glutathione, which can be depleted by oxidation to the disulfide form, GSSG [17]. tBHP rapidly depletes GSH in G6PD-deficient erythrocytes, while normal erythrocytes are unaffected [18]. Excessive lipid peroxidation induced by tBHP disrupts membrane and causes hemolysis [19]. GSH and ascorbate rapidly scavenge tBHP-derived radicals and protects membrane [20]. Supplementation of vitamins C and E partially restores GSH and reduces hemolysis in tBHP-administered erythrocytes [21]. These findings indicate that $\mathrm{tBHP}$ alters redox homeostasis, in part, by interfering with the GSH/GSSG balance. 
Lipid peroxidation is increased in embryos of reduced GSPD-1 activity, which is linked to embryonic impairment [6]. However, a direct link between lipid peroxidation and embryonic lethality has not been clearly established in C. elegans. In the current study, tBHP induces lipid peroxidation as indicated by enhanced MDA production. Such increased lipid peroxidation is analogous to that found in GSPD-1-deficient embryos [6]. These findings provide a foundation for justifying the use of tBHP as an inducer of lipid peroxidation for investigating the downstream events of GSPD-1 deficiency and, subsequently, altered embryonic development.

Although tBHP elicits an oxidative stress response in C. elegans [22], how it causes embryonic defects via lipid peroxidation needs to be further delineated. tBHP has been proposed to diffuse into cytosol and forms radicals, which react with membrane lipids to initiate peroxidation [23]. The peroxidation of membrane phospholipids (polyunsaturated fatty acids) causes the formation of reactive aldehydes and membrane disruption, including disturbed membrane permeability and fluidity [24]. Such phenomena are in accordance with membrane-associated embryonic defects, including altered permeability, polarity and cytokinesis, as observed in GSPD-1-deficient C. elegans embryos [6]. These defects are linked to the disturbed membrane lipid composition caused by the activation of iPLA due to elevated lipid peroxidation in GSPD-1-deficient $C$. elegans embryos. HBHP and $\mathrm{H}_{2} \mathrm{O}_{2}$ have been reported to alter the composition of phospholipids in primary neocortical cells [25], which is analogous to the altered phospholipid profile in GSPD-1-deficient C. elegans adults [6].

In addition, phospholipase $\mathrm{A}_{2}\left(\mathrm{PLA}_{2}\right)$ has been reported to play a role in $\mathrm{tBHP}$-induced cell death of other cells [26]. tBHP can induce PLA $\mathrm{P}_{2}$-mediated hepatocyte cell death. An inhibitor of PLA, mepacrine, blocks the release of arachidonic acid by tBHP, suggesting that activation of $\mathrm{PLA}_{2}$ is required for $\mathrm{tBHP}$-induced cell injury [27]. The proposed involvement of iPLA is supported by the finding that tBHP or $\mathrm{H}_{2} \mathrm{O}_{2}$ induced neural cell death is mediated by iPLA activity [26]. An inverse correlation has been shown between iPLA activity and G6PD activity in C. elegans during embryogenesis [6]. In fact, oxidative damage, such as lipid peroxidation, has long been recognized to induce $\mathrm{PLA}_{2}$ activity, leading to altered lipid composition in membrane [28].

The proposed iPLA activation by tBHP in C. elegans is further supported by the findings that $5 \mathrm{mM}$ tBHP increased iPLA activity in mock C. elegans, while this effect was less in GSPD-1 deficiency (Figure 5). Such findings are consistent with the postulate that, once the buildup of lipid peroxidation in germ cell death (Figure 3) and lipid peroxidation as measured by MDA formation (Figure 4) has reached a critical concentration, additional oxidative stress will have minimal effects in these situations. Although lipid peroxidation may be associated with impaired oogenesis [29], the link between lipid peroxidation and germ cell death has not been established in C. elegans. The increased MDA in gspd-1-knockdown C. elegans is consistent with a previous report that G6PD deficiency enhances oxidative stress as indicated by the ROS-sensitive dye DCFDA [5]. The cytotoxicity of tBHP has also been linked to oxidative stress and apoptosis in a similar manner as with severe G6PD deficiency [30-37]. Hence, tBHP enhanced MDA levels and stimulated iPLA activity by MDA in GSPD-1 deficient $C$. elegans are strong evidence indicative of a direct involvement of lipid peroxidation in germ cells death and impaired embryogenesis during embryonic development in C. elegans.

\section{Materials and Methods}

\subsection{Worm Culture}

N2 (wild type) C. elegans was acquired from Caenorhabditis Genetics Center (University of Minnesota, Minneapolis, MN, USA). A reporter strain of bcIs39 [ $\mathrm{P}_{\text {lim-7 }}$ ced-1::gfp;lin-15(+)] for detecting germ cell apoptosis [13] was a gift from Prof. Szecheng John Lo (Department of Biomedical Sciences, Chang Gung University, Taoyuan, Taiwan). Nematode strains were cultured on a nematode growth medium (NGM) agar plate seeded with bacterial lawn at $20^{\circ} \mathrm{C}$ according to standard procedures [38]. 


\section{2. gspd-1 RNAi Knockdown}

RNAi knockdown was performed by feeding dsRNA-expressed bacteria according to a standard procedure [39]. In brief, gravid hermaphrodites fed on E. coli OP50 were administered with hypochlorite bleach. Eggs were incubated in M9 buffer overnight to obtain synchronized L1 larvae, which were cultured on NGM agar containing $1 \mathrm{mM}$ IPTG, antibiotics (ampicillin and carbenicillin) (Sigma-Aldrich, St. Louis, MO, USA), and seeded with HT115 E. coli expressing L4440 vector control (mock) or a gspd-1 RNAi described previously [5].

\subsection{Reverse Transcription and Quantitative PCR ( $q P C R$ )}

Total RNA of C. elegans samples were extracted using TRIzol ${ }^{\circledR}$ (Invitrogen, Carlsbad, CA, USA). cDNA was synthesized from $1 \mu \mathrm{g}$ of the total RNA by the use of an iScript cDNA synthesis kit (Bio-Rad, Hercules, CA, USA). Quantitative PCR was performed by using a Bio-Rad iQ5 and a SYBR Green Supermix reagent (Yeastern Biotech, New Taipei City, Taiwan). Primers for amplify gspd-1 were as follows: forward primer, $5^{\prime}$-atgctcttgctgttgttcacatc- $3^{\prime}$; reverse primer, $5^{\prime}$-cgctttaattcaccagacggatag- $3^{\prime}$. The thermal cycle program was as follows: $95^{\circ} \mathrm{C}$ for $10 \mathrm{~min}, 40$ cycles of $95^{\circ} \mathrm{C}$ for $15 \mathrm{~s}$ and $60^{\circ} \mathrm{C}$ for $1 \mathrm{~min}$. The expression level of $g s p d-1$ was normalized to threshold cycle $(\mathrm{Ct})$ values of the housekeeping gene (beta-actin: forward primer, $5^{\prime}$-tcggtatgggacagaaggac-3'; reverse primer, $5^{\prime}$-catcccagttggtgacgata-3').

\section{4. tBHP Administration}

For short-term tBHP administration, the L4 stage of mock or the gspd-1-knockdown C. elegans was collected by washing NGM plate with M9 buffer. The C. elegans samples were transferred to a $15 \mathrm{~mL}$ tube; soaked in $10 \mathrm{~mL}$ of M9 buffer containing 0.5, 1, or $5 \mathrm{mM} \mathrm{tBHP} \mathrm{(Sigma-Aldrich,} \mathrm{St.} \mathrm{Louis,}$ $\mathrm{MO}, \mathrm{USA}$ ); and placed on a shaker for $30 \mathrm{~min}$ at room temperature. Subsequently, tBHP-administered worms were washed twice with the M9 buffer and centrifuged at $1500 \times g$ for $2 \mathrm{~min}$ to remove residual tBHP followed by transferring to a fresh NGM plate and kept overnight at $20^{\circ} \mathrm{C}$.

\subsection{Brood Size Determination}

Staged L4 C. elegans hermaphrodites were administered with tBHP and recovered on RNAi plates. These worms were transferred daily to fresh RNAi NGM plates during the egg-laying period. After 2-3 days, the viable progenies hatched from the eggs were counted by using a dissecting microscope (Nikon SMZ645, Tokyo, Japan). At least 20 worms were scored in each experiment.

\subsection{Germline Apoptosis Assay}

A reporter strain, bcIs39 [ $\mathrm{P}_{\text {lim- }}$ ced-1::gfp;lin-15(+)], was used to determine germ cell apoptosis by visualizing the signal of CED-1::GFP, which indicates the dying germ cell engulfed by the somatic sheath cell [13]. The number of apoptotic germ cells was quantified by counting the surrounding GFP signal in the gonad arm. Young adults of mock and gspd-1-knockdown C. elegans administered with the indicated concentrations of tBHP were anesthetized with $2 \%$ levamisole followed by mounting on a slide with a $2 \%$ agarose pad [5]. Fluorescent microscopic images were taken by using a fluorescence microscope (Leica DM 2500; Leica, Wetzlar, Germany) coupled with a CCD camera (Photometrics, Coolsnap K4, Tucson, AZ, USA) followed by analysis with imaging software (Image J 1.51j8 (Wayne Rasband, Bethesda, MD, USA)).

\subsection{MDA Assay}

Malondialdehyde was measured by using the Oxiselect thiobarbituric acid reactive substances assay kit (Cell Biolabs, San Diego, CA, USA). The C. elegans lysate was prepared according to a previous protocol [6]. A $50 \mu \mathrm{L}$ worm pellet was used for a single test. Upon homogenization by sonication, a $100 \times$ BHT solution was added immediately to achieve a final concentration of $1 \times$ to 
prevent further oxidation of MDA in the sample. The lysate was then centrifuged at $10,000 \times g$ for $5 \mathrm{~min}$. The supernatant was collected for the MDA assay according to the manufacturer's protocol.

\section{8. iPLA Assay}

The iPLA activity was measured by using the $\mathrm{CPLA}_{2}$ assay kit (Cayman Chemical, Ann Arbor, MI, USA) with modification [6]. For determining iPLA activity, the assay buffer was substituted with a calcium-free buffer which consisted of $300 \mathrm{mM} \mathrm{NaCl}, 60 \%$ glycerol, $10 \mathrm{mM}$ HEPES, $8 \mathrm{mM}$ Triton X-100, $4 \mathrm{mM}$ EGTA and $2 \mathrm{mg} / \mathrm{mL}$ of BSA. Synchronized C. elegans adults were washed from the NGM plate. After homogenization by sonication, worm lysates were centrifuged at $10,000 \times g$ for $15 \mathrm{~min}$ at $4{ }^{\circ} \mathrm{C}$. The supernatants were collected for subsequent procedures according to a previous report [6].

\subsection{Statistical Analysis}

All statistical analyses were conducted using Prism 8.4.3 (471) version for MacOS (GraphPad 8, San Diego, CA, USA). Data of three independent experiments are presented as mean \pm SD. The statistical difference between the control and experimental groups was analyzed by independent student's $t$-test. $p$-values below 0.05 were considered statistically significant.

Author Contributions: Conceptualization, H.-C.Y., A.S. and D.T.-Y.C.; methodology, H.Y.; formal analysis, H.Y.; resources, H.-C.Y. and D.T.-Y.C.; data curation, T.-H.M. and W.-Y.T.; writing-original draft preparation, H.-C.Y. and H.Y.; writing-review and editing, T.-H.M., W.-Y.T., D.T.-Y.C. and A.S.; visualization, T.-H.M.; project administration, T.-H.M. and W.-Y.T.; and funding acquisition, H.-C.Y. and D.T.-Y.C. All authors have read and agreed to the published version of the manuscript.

Funding: This research was funded by the Ministry of Science and Technology, Taiwan (MOST108-2320-B-264-002 and MOST109-2320-B-264-001-MY2 to H.-C.Y. and MOST109-2320-B-255-009 and MOST109-2811-B-255-501 to D.T.-Y.C.) and the grant from Chang Gung Memorial Hospital (CMRPF1J0072 to D.T.-Y.C.).

Conflicts of Interest: The authors declare no conflict of interest.

\section{Abbreviations}

G6PD glucose-6-phosphate dehydrogenase

NADPH nicotinamide adenine dinucleotide phosphate

tBHP tert-butyl hydroperoxide

MDA malondialdehyde

iPLA calcium-independent phospholipase $\mathrm{A}_{2}$

\section{References}

1. Yang, H.C.; Wu, Y.H.; Yen, W.C.; Liu, H.Y.; Hwang, T.L.; Stern, A.; Chiu, D.T. The Redox Role of G6PD in Cell Growth, Cell Death, and Cancer. Cells 2019, 8, 1055. [CrossRef] [PubMed]

2. Yang, H.C.; Cheng, M.L.; Ho, H.Y.; Chiu, D.T. The microbicidal and cytoregulatory roles of NADPH oxidases. Microbes Infect. 2011, 13, 109-120. [CrossRef] [PubMed]

3. Beutler, E. G6PD deficiency. Blood 1994, 84, 3613-3636. [CrossRef] [PubMed]

4. Longo, L.; Vanegas, O.C.; Patel, M.; Rosti, V.; Li, H.; Waka, J.; Merghoub, T.; Pandolfi, P.P.; Notaro, R.; Manova, K.; et al. Maternally transmitted severe glucose 6-phosphate dehydrogenase deficiency is an embryonic lethal. EMBO J. 2002, 21, 4229-4239. [CrossRef] [PubMed]

5. Yang, H.C.; Chen, T.L.; Wu, Y.H.; Cheng, K.P.; Lin, Y.H.; Cheng, M.L.; Ho, H.Y.; Lo, S.J.; Chiu, D.T. Glucose 6-phosphate dehydrogenase deficiency enhances germ cell apoptosis and causes defective embryogenesis in Caenorhabditis elegans. Cell Death Dis. 2013, 4, e616. [CrossRef] [PubMed]

6. Chen, T.L.; Yang, H.C.; Hung, C.Y.; Ou, M.H.; Pan, Y.Y.; Cheng, M.L.; Stern, A.; Lo, S.J.; Chiu, D.T. Impaired embryonic development in glucose-6-phosphate dehydrogenase-deficient Caenorhabditis elegans due to abnormal redox homeostasis induced activation of calcium-independent phospholipase and alteration of glycerophospholipid metabolism. Cell Death Dis. 2017, 8, e2545. [CrossRef] [PubMed] 
7. Ayyadevara, S.; Engle, M.R.; Singh, S.P.; Dandapat, A.; Lichti, C.F.; Benes, H.; Shmookler Reis, R.J.; Liebau, E.; Zimniak, P. Lifespan and stress resistance of Caenorhabditis elegans are increased by expression of glutathione transferases capable of metabolizing the lipid peroxidation product 4-hydroxynonenal. Aging Cell 2005, 4, 257-271. [CrossRef] [PubMed]

8. Sakamoto, T.; Maebayashi, K.; Tsunoda, Y.; Imai, H. Inhibition of lipid peroxidation during the reproductive period extends the lifespan of Caenorhabditis elegans. J. Clin. Biochem. Nutr. 2020, 66, 116-123. [CrossRef]

9. Singh, S.P.; Niemczyk, M.; Zimniak, L.; Zimniak, P. Fat accumulation in Caenorhabditis elegans triggered by the electrophilic lipid peroxidation product 4-hydroxynonenal (4-HNE). Aging (Albany N. Y.) 2008, 1, 68-80. [CrossRef]

10. Rush, G.F.; Gorski, J.R.; Ripple, M.G.; Sowinski, J.; Bugelski, P.; Hewitt, W.R. Organic hydroperoxide-induced lipid peroxidation and cell death in isolated hepatocytes. Toxicol. Appl. Pharmacol. 1985, 78, 473-483. [CrossRef]

11. Ayala, A.; Munoz, M.F.; Arguelles, S. Lipid peroxidation: Production, metabolism, and signaling mechanisms of malondialdehyde and 4-hydroxy-2-nonenal. Oxid. Med. Cell Longev. 2014, 2014, 360438. [CrossRef] [PubMed]

12. Hix, S.; Kadiiska, M.B.; Mason, R.P.; Augusto, O. In vivo metabolism of tert-butyl hydroperoxide to methyl radicals. EPR spin-trapping and DNA methylation studies. Chem. Res. Toxicol. 2000, 13, 1056-1064. [CrossRef] [PubMed]

13. Zhou, Z.; Hartwieg, E.; Horvitz, H.R. CED-1 is a transmembrane receptor that mediates cell corpse engulfment in C. elegans. Cell 2001, 104, 43-56. [CrossRef]

14. Yang, H.C.; Wu, Y.H.; Liu, H.Y.; Stern, A.; Chiu, D.T. What has passed is prolog: New cellular and physiological roles of G6PD. Free Radic. Res. 2016, 50, 1047-1064. [CrossRef] [PubMed]

15. Yang, H.C.; Yu, H.; Liu, Y.C.; Chen, T.L.; Stern, A.; Lo, S.J.; Chiu, D.T. IDH-1 deficiency induces growth defects and metabolic alterations in GSPD-1-deficient Caenorhabditis elegans. J. Mol. Med. (Berl.) 2019, 97, 385-396. [CrossRef] [PubMed]

16. Davies, M.J. Detection of peroxyl and alkoxyl radicals produced by reaction of hydroperoxides with rat liver microsomal fractions. Biochem. J. 1989, 257, 603-606. [CrossRef]

17. Crane, D.; Haussinger, D.; Graf, P.; Sies, H. Decreased flux through pyruvate dehydrogenase by thiol oxidation during t-butyl hydroperoxide metabolism in perfused rat liver. Hoppe Seylers Z. Physiol. Chem. 1983, 364, 977-987. [CrossRef]

18. Bozzi, A.; Parisi, M.; Strom, R. Erythrocyte glutathione determination in the diagnosis of glucose-6-phosphate dehydrogenase deficiency. Biochem. Mol. Biol. Int. 1996, 40, 561-569. [CrossRef]

19. Trotta, R.J.; Sullivan, S.G.; Stern, A. Lipid peroxidation and haemoglobin degradation in red blood cells exposed to t-butyl hydroperoxide. The relative roles of haem- and glutathione-dependent decomposition of t-butyl hydroperoxide and membrane lipid hydroperoxides in lipid peroxidation and haemolysis. Biochem. J. 1983, 212, 759-772. [CrossRef]

20. Trotta, R.J.; Sullivan, S.G.; Stern, A. Lipid peroxidation and haemoglobin degradation in red blood cells exposed to t-butyl hydroperoxide. Effects of the hexose monophosphate shunt as mediated by glutathione and ascorbate. Biochem. J. 1982, 204, 405-415. [CrossRef]

21. Chaves, M.A.; Leonart, M.S.; do Nascimento, A.J. Oxidative process in erythrocytes of individuals with hemoglobin S. Hematology 2008, 13, 187-192. [CrossRef] [PubMed]

22. Ewald, C.Y.; Hourihan, J.M.; Blackwell, T.K. Oxidative Stress Assays (arsenite and tBHP) in Caenorhabditis elegans. Bio Protoc. 2017, 7. [CrossRef] [PubMed]

23. Brault, D.; Neta, P.; Patterson, L.K. The lipid peroxidation model for halogenated hydrocarbon toxicity. Kinetics of peroxyl radical processes involving fatty acids and Fe(III) porphyrins. Chem. Biol. Interact. 1985, 54, 289-297. [CrossRef]

24. Kucera, O.; Endlicher, R.; Rousar, T.; Lotkova, H.; Garnol, T.; Drahota, Z.; Cervinkova, Z. The effect of tert-butyl hydroperoxide-induced oxidative stress on lean and steatotic rat hepatocytes in vitro. Oxid. Med. Cell. Longev. 2014, 2014, 752506. [CrossRef] [PubMed]

25. Peterson, B.; Stovall, K.; Monian, P.; Franklin, J.L.; Cummings, B.S. Alterations in phospholipid and fatty acid lipid profiles in primary neocortical cells during oxidant-induced cell injury. Chem. Biol. Interact. 2008, 174, 163-176. [CrossRef] 
26. Peterson, B.; Knotts, T.; Cummings, B.S. Involvement of Ca2+-independent phospholipase A2 isoforms in oxidant-induced neural cell death. Neurotoxicology 2007, 28, 150-160. [CrossRef] [PubMed]

27. Martin, C.; Martinez, R.; Navarro, R.; Ruiz-Sanz, J.I.; Lacort, M.; Ruiz-Larrea, M.B. tert-Butyl hydroperoxide-induced lipid signaling in hepatocytes: Involvement of glutathione and free radicals. Biochem. Pharmacol. 2001, 62, 705-712. [CrossRef]

28. McLean, L.R.; Hagaman, K.A.; Davidson, W.S. Role of lipid structure in the activation of phospholipase A2 by peroxidized phospholipids. Lipids 1993, 28, 505-509. [CrossRef]

29. Erol, B.; Bozlu, M.; Hanci, V.; Tokgoz, H.; Bektas, S.; Mungan, G. Coenzyme Q10 treatment reduces lipid peroxidation, inducible and endothelial nitric oxide synthases, and germ cell-specific apoptosis in a rat model of testicular ischemia/reperfusion injury. Fertil. Steril. 2010, 93, 280-282. [CrossRef]

30. Li, Y.; Wu, Y.; Jiang, K.; Han, W.; Zhang, J.; Xie, L.; Liu, Y.; Xiao, J.; Wang, X. Mangiferin Prevents TBHP-Induced Apoptosis and ECM Degradation in Mouse Osteoarthritic Chondrocytes via Restoring Autophagy and Ameliorates Murine Osteoarthritis. Oxid. Med. Cell. Longev. 2019, 2019, 8783197. [CrossRef]

31. Loch-Caruso, R.; Korte, C.S.; Hogan, K.A.; Liao, S.; Harris, C. Tert-Butyl Hydroperoxide Stimulated Apoptosis Independent of Prostaglandin E2 and IL-6 in the HTR-8/SVneo Human Placental Cell Line. Reprod. Sci. 2020. [CrossRef] [PubMed]

32. Lucarelli, G.; Galleggiante, V.; Rutigliano, M.; Sanguedolce, F.; Cagiano, S.; Bufo, P.; Lastilla, G.; Maiorano, E.; Ribatti, D.; Giglio, A.; et al. Metabolomic profile of glycolysis and the pentose phosphate pathway identifies the central role of glucose-6-phosphate dehydrogenase in clear cell-renal cell carcinoma. Oncotarget 2015, 6, 13371-13386. [CrossRef] [PubMed]

33. Saha, S.; Mahalanobish, S.; Dutta, S.; Sil, P.C. Mangiferin ameliorates collateral neuropathy in tBHP induced apoptotic nephropathy by inflammation mediated kidney to brain crosstalk. Food Funct. 2019, 10, 5981-5999. [CrossRef] [PubMed]

34. Tang, Q.; Zheng, G.; Feng, Z.; Chen, Y.; Lou, Y.; Wang, C.; Zhang, X.; Zhang, Y.; Xu, H.; Shang, P.; et al. Trehalose ameliorates oxidative stress-mediated mitochondrial dysfunction and ER stress via selective autophagy stimulation and autophagic flux restoration in osteoarthritis development. Cell Death Dis. 2017, 8 , e3081. [CrossRef] [PubMed]

35. Ye, S.; Wang, W.; Chen, X.; Deng, Y. Sesamin promotes angiogenesis and accelerates wound healing in rats via alleviates TBHP-induced apoptosis in human umbilical vein endothelial cells. Biosci. Biotechnol. Biochem. 2020, 84, 887-897. [CrossRef] [PubMed]

36. Zhao, C.; Li, T.; Han, B.; Yue, W.; Shi, L.; Wang, H.; Guo, Y.; Lu, Z. DDAH1 deficiency promotes intracellular oxidative stress and cell apoptosis via a miR-21-dependent pathway in mouse embryonic fibroblasts. Free Radic. Biol. Med. 2016, 92, 50-60. [CrossRef]

37. Zheng, G.; Zhan, Y.; Li, X.; Pan, Z.; Zheng, F.; Zhang, Z.; Zhou, Y.; Wu, Y.; Wang, X.; Gao, W.; et al. TFEB, a potential therapeutic target for osteoarthritis via autophagy regulation. Cell Death Dis. 2018, 9, 858. [CrossRef]

38. Girard, L.R.; Fiedler, T.J.; Harris, T.W.; Carvalho, F.; Antoshechkin, I.; Han, M.; Sternberg, P.W.; Stein, L.D.; Chalfie, M. WormBook: The online review of Caenorhabditis elegans biology. Nucleic Acids Res. 2007, 35, D472-D475. [CrossRef]

39. Kamath, R.S.; Fraser, A.G.; Dong, Y.; Poulin, G.; Durbin, R.; Gotta, M.; Kanapin, A.; Le Bot, N.; Moreno, S.; Sohrmann, M.; et al. Systematic functional analysis of the Caenorhabditis elegans genome using RNAi. Nature 2003, 421, 231-237. [CrossRef]

Publisher's Note: MDPI stays neutral with regard to jurisdictional claims in published maps and institutional affiliations.

(C) 2020 by the authors. Licensee MDPI, Basel, Switzerland. This article is an open access article distributed under the terms and conditions of the Creative Commons Attribution (CC BY) license (http://creativecommons.org/licenses/by/4.0/). 